\title{
Systematic Cloning of Treponema pallidum Open Reading Frames for Protein Expression and Antigen Discovery
}

\author{
Matthew McKevitt, ${ }^{1}$ Krupa Patel, ${ }^{1}$ David Smajs, ${ }^{4}$ Michael Marsh, ${ }^{2}$ \\ Melanie McLoughlin, ${ }^{5}$ Steven J. Norris, ${ }^{4,5}$ George M. Weinstock, ${ }^{3}$ \\ and Timothy Palzkill ${ }^{1,6}$ \\ ${ }^{1}$ Department of Molecular Virology and Microbiology, ${ }^{2}$ Structural and Computational Biology and Molecular Biophysics
Program, and ${ }^{3}$ Human Genome Sequencing Center, Baylor College of Medicine, Houston, Texas 77030, USA;
${ }^{4}$ Department of Microbiology and Molecular Genetics and ${ }^{5}$ Department of Pathology and Laboratory Medicine, University
of Texas-Houston Medical School, Houston, Texas 77030, USA
}

A topoisomerase-based method was used to clone PCR products encoding 991 of the 1041 open reading frames identified in the genome sequence of the bacterium that causes syphilis, Treponema pallidum subsp. pallidum. Cloning the open reading frames into the univector plasmid system permitted the rapid conversion of the original clone set to other functional vectors containing a variety of promoters or tag sequences. A computational prediction of signal sequences identified $248 \mathrm{~T}$. pallidum proteins that are potentially secreted from the cell. These clones were systematically converted into vectors designed to express the encoded proteins as glutathione-S-transferase fusion proteins. To test the potential of the clone set for novel antigen discovery, 85 of these fusion proteins were expressed from Escherichia coli, partially purified, and tested for antigenicity by using sera from rabbits infected with $T$. pallidum. Twelve of the 85 proteins bound significant levels of antibody. Of these 12 proteins, seven had previously been identified as $T$. pallidum antigens, and the remaining five represent novel antigens. These results demonstrate the potential of the $T$. pallidum clone set for antigen discovery and, more generally, for advancing the biology of this enigmatic spirochete.

[Supplemental material is available online at www.genome.org.]

The genome sequences of many infectious microorganisms have now been determined. The availability of genome sequence information will enable new approaches to be developed to determine the function of gene products and their possible role in pathogenesis. A proteomics approach is being developed to identify proteins important for the Treponema pallidum host-pathogen interaction. As a first step, an efficient high-throughput strategy has been used to clone $96 \%$ of the predicted $T$. pallidum open reading frames (ORFs) into a recombination-based vector system.

T. pallidum is the causative agent of syphilis. Syphilis is a multistage infection characterized by localized, disseminated, and chronic manifestations interspersed between periods of latent infection. The molecular mechanisms of $T$. pallidum pathogenesis are poorly understood (Norris et al. 2001). The organism is an obligate human pathogen that has not been cultured continuously in vitro (Norris et al. 2001), precluding the use of many experimental approaches, including direct genetic analysis. Thus, new methods are needed to address questions about the biology and pathogenesis of this organism.

The complete genome sequence of $T$. pallidum was determined in 1998 (Fraser et al. 1998). It consists of a circular

${ }^{6}$ Corresponding author.

E-MAIL timothyp@bcm.tmc.edu; FAX (713) 798-7375.

Article and publication are at http://www.genome.org/cgi/doi/10.1101/ gr.288103. Article published online before print in June 2003. chromosome of $\sim 1100 \mathrm{~kb}$ and is therefore one of the smallest known prokaryotic genomes (Fraser et al. 1998). There are a total of 1041 predicted ORFs that encompass $93 \%$ of the total genomic DNA (Fraser et al. 1998). Biological roles were predicted for $55 \%$ of the ORFs based on matches to ORFs of known function from other organisms; $17 \%$ of the ORFs correspond to hypothetical proteins from other species, and 28\% of the ORFs are novel genes (Fraser et al. 1998).

A number of factors make the $T$. pallidum genome an excellent model system for the development of functional genomic techniques. These factors include the small size of the genome, the correspondingly small number of ORFs, and the intractability of this organism to standard genetic approaches. Important questions regarding T. pallidum biology that a functional genomics approach can address include the identification of antigenic proteins that may aid in diagnostics and vaccine development, and identification of proteins important for attachment and invasion of human tissues.

\section{RESULTS AND DISCUSSION}

\section{Construction of the T. pallidum Univector Clone Set}

The purpose of this study was to develop a complete set of $T$. pallidum genes cloned into a variety of plasmids useful for protein expression and purification in Escherichia coli, as well as other functional vectors useful for methods such as phage 
display and two-hybrid system protein interaction studies. This goal was accomplished by using a recombination-based approach developed by Liu et al. (1998) to facilitate the cloning of a PCR product into a plasmid, followed by the rapid conversion of the plasmid to a number of different expression systems without the necessity of cloning the PCR product multiple independent times. The method, termed the univector plasmid fusion system (UPS), involves the insertion of a gene into the univector plasmid (in this case, pUNI-D) and subsequent fusion of the gene to a variety of promoters and tag sequences. The system is based upon plasmid fusion using the Cre-loxP site-specific recombination system of bacteriophage P1 (Fig. 1; Sternberg et al. 1981). The pUNI plasmid is used for the initial cloning of PCR products, whereas the pHOST plasmid contains the appropriate promoter or tag se-

A.

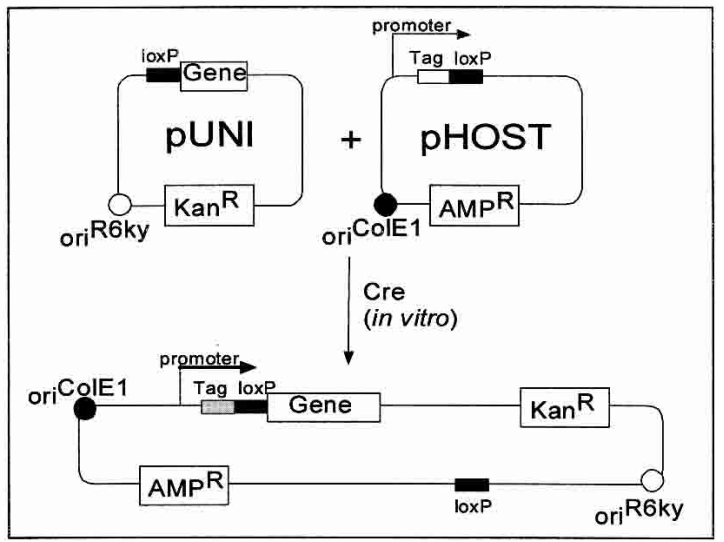

B.

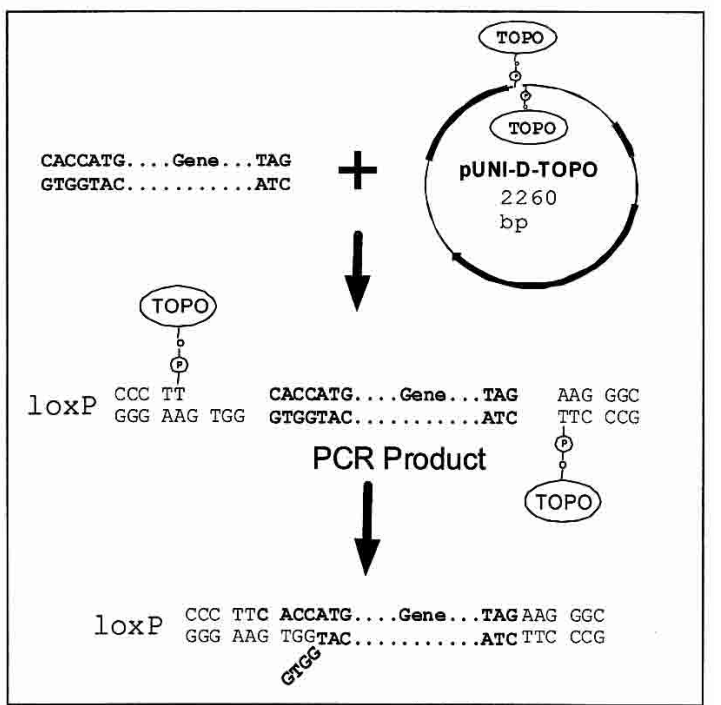

Figure $1(A)$ Univector plasmid fusion system. Cre-loxP-mediated site-specific recombination fuses the pUNI and pHOST plasmids at the loxp site. As a result, the gene of interest is placed under the control of the $\mathrm{pHOST}$ promoter and fused to any tag sequences present in the pHOST plasmid. Figure adapted from Liu et al. (1998). (B) Schematic illustration of directional topoisomerase cloning into the pUNI-D vector. The sequence $5^{\prime}$-CACC is required at the $5^{\prime}$ end of the PCR product for directional topoisomerase-mediated cloning. The oval represents vaccinia virus topoisomerase I. In the example shown, the $5^{\prime}$-CACC sequence is appended immediately $5^{\prime}$ of the ATC start codon of the gene to be inserted. quences for creating fusion proteins. The recombinant protein expression construct is made by fusion of the pUNI and pHOST plasmids via Cre-loxP site-specific recombination (Fig. 1; Liu et al. 1998).

Insertion of T. pallidum ORFs in a univector was accomplished by using a cloning method based on the mechanism of action of the vaccinia virus DNA topoisomerase I (Shuman 1994). In the reaction, the topoisomerase forms a covalent complex with the vector DNA, and PCR products that contain a 5' hydroxyl tail complementary to the sequence on the covalent adduct can be inserted to create a recombinant molecule (Shuman 1994). The cloning method has recently been improved to allow directional cloning of PCR products (Invitrogen; Fig. 1). The only requirement for PCR primer design for this system is to include the sequence $5^{\prime}$-CACC in the primer sequence at the $5^{\prime}$ end of the PCR product. The $5^{\prime}$-CACC sequence is complementary to a sequence on the $5^{\prime}$ side of the plasmid-topoisomerase I adduct and, as such, controls the orientation of insertion of the PCR product (Fig. 1B).

The annotated $T$. pallidum genome sequence deposited in GenBank includes the sequence position of the start and stop codons of each ORF (Fraser et al. 1998). Frameshifts were identified in 10 ORFs, reducing the GenBank deposit from 1041 to 1031 ORFs. To amplify each of the 1031 ORFs, a computer program was written that used the GenBank annotation data to design primers complementary to the initial and final $25 \mathrm{bp}$ of each ORF. The initial 240 nucleotides of each ORF were also translated and submitted to a signal sequence prediction program (SignalP http://www.cbs.dtu.dk/ services/SignalP/). Conserved signal peptidase I or II signal sequences were predicted for 248 ORFs; however, only 183 predictions appeared reasonable based on length of the encoded gene and/or signal sequence. Primers were therefore designed to amplify only the portion of the ORF encoding the mature portion of these 183 proteins. The complete set of 2062 primers necessary to amplify all of the predicted T. pallidum genes were designed by using the program, synthesized, and used for PCR amplification. The template DNA for the PCR reactions consisted of $T$. pallidum genomic DNA and a set of large insert bacterial artificial chromosome (BAC) clones encompassing the entire T. pallidum genome (Smajs et al. 2002).

In the initial PCR reactions, 959 of the 1031 ORFs were successfully amplified by using the primers designed with 25 bp of complementary nucleotides. Inspection of primer pairs for the ORFs that failed to amplify indicated that below average $T_{m}$ values for the primers might have been responsible for the lack of amplification of 61 of these ORFs. The region of complementarity in these primers was extended to $30 \mathrm{bp}$, and subsequent amplification yielded PCR product for 38 of the 61 genes. In addition to extending the length of primers, increasing the annealing/extension parameter of the PCR cycling program aided in acquiring PCR products for an additional 26 ORFs. To date, 1023 of the 1031 predicted genes have been successfully amplified by PCR.

Of the 1023 PCR products, 991 have been inserted into the pUNI-D vector by using the topoisomerase cloning method. Briefly, PCR products were inserted into pUNI-D (Fig. 1), transformed into E. coli, and selected on Luria Bertani (LB) agar plates containing kanamycin. Transformants were screened by using a PCR technique that identifies ORFs of the correct size cloned into pUNI-D in the correct orientation.

The T. pallidum ORFs that have not been cloned successfully are listed in a table available at www.genome.org as

\section{Genome Research}


Table 1. Mutation Sequence Data

\begin{tabular}{|c|c|c|c|c|c|}
\hline & TP ORF & $\begin{array}{l}\text { Number of base } \\
\text { calls from } 5^{\prime} \\
\text { end of gene }\end{array}$ & Result & $\begin{array}{l}\text { Number of base } \\
\text { calls from } 3^{\prime} \\
\text { end of gene }\end{array}$ & Result \\
\hline & 11 & 651 & & 696 & error type $2^{a}$ \\
\hline & $13^{b}$ & 592 & error type $3^{c}$ & & \\
\hline & 74 & 664 & error type $3^{c}$ & 325 & error type $2^{a}$ \\
\hline & 117 & 874 & & 678 & error type $3^{d}$ \\
\hline & 174 & 718 & error type $5^{e}$ & & \\
\hline & 212 & 230 & & 315 & error type $1^{a}$ \\
\hline & $247^{b}$ & 970 & & & error type $2^{a}$ \\
\hline & 252 & 647 & error type $6^{e}$ & 663 & \\
\hline & $260^{b}$ & 1237 & & & error type $2^{a}$ \\
\hline & $309^{b}$ & 793 & & & error type $2^{a}$ \\
\hline & 324 & 769 & & 383 & error type $7^{e}$ \\
\hline & $350^{b}$ & 1291 & error type $3^{c}$ & & \\
\hline & 389 & 294 & & 299 & error type $1^{a}$ \\
\hline & $415^{b}$ & 535 & error type $6^{e}$ & & \\
\hline & 459 & 710 & error type $4^{e}$ & & \\
\hline & 471 & 181 & & 660 & error type $3^{c}$ \\
\hline & $536^{b}$ & 330 & error type $8^{e}$ & & \\
\hline & 602 & 480 & error type $4^{e}$ & & \\
\hline & 692 & 250 & & 306 & error type $1^{a}$ \\
\hline & $708^{b}$ & 424 & error type $3^{c}$ & & \\
\hline & 711 & 505 & error type $3^{c}$ & & \\
\hline & 747 & 590 & error type $3^{a}$ & & \\
\hline & $782^{b}$ & 385 & error type $3^{c}$ & & \\
\hline & 792 & 270 & & 400 & error type $1^{a}$ \\
\hline & 943 & 280 & error type $4^{e}$ & 300 & \\
\hline & 1031 & 736 & & 657 & error type $2^{a}$ \\
\hline Table count & 26 & 15,406 & 13 & 5682 & 14 \\
\hline Total count & 108 & 57,756 & 13 & 14,431 & 14 \\
\hline \multirow{3}{*}{\multicolumn{5}{|c|}{$\begin{array}{l}\text { Total number of nucleotides sequenced } \\
\text { Total number of nucleotides cloned } \\
\text { Total percentage sequenced }\end{array}$}} & 72,187 \\
\hline & & & & & $1,044,638$ \\
\hline & & & & & $6.9 \%$ \\
\hline \multicolumn{6}{|c|}{$\begin{array}{l}\text { Error type } 1 \text { indicates last nucleotide deleted; error type } 2 \text {, multiple nucleotides deleted; error type } \\
3 \text {, nucleotide substitution; error type } 4 \text {, single nucleotide deletion inside primer region; error type } \\
5 \text {, single nucleotide deletion outside primer region; error type } 6 \text {, multiple nucleotide deletions } \\
\text { inside primer region; error type } 7 \text {, nucleotide insertion outside primer region; and error type } 8 \text {, } \\
\text { nucleotide insertion inside primer region. } \\
{ }^{a} \text { Results in silent mutation. } \\
{ }^{b} \text { Entire gene sequenced. } \\
{ }^{C} \text { Results in mis-sense mutation. } \\
{ }^{d} \text { Results in non-sense mutation. } \\
{ }^{e} \text { Results in frameshift mutation. }\end{array}$} \\
\hline
\end{tabular}

some of the cloned ORFs. To determine the frequency of errors among the cloned ORFs, DNA sequence information was obtained from 106 clones (data available in Supplemental Materials). Sequence data was acquired by sequencing into each gene from both the $5^{\prime}$ and $3^{\prime}$ ends with primers located $\sim 100$ nucleotides away from the cloned gene. A total of 72,187 nucleotides were sequenced, representing $6.9 \%$ of all nucleotides cloned. From this analysis, 27 mutations were identified, which corresponds to one error per $2673 \mathrm{bp}$ sequenced (Table $1)$.

Of the 27 mutations identified by sequencing, nine are predicted to result in frameshift or nonsense mutations and, therefore, to encode nonfunctional protein products. Five of these nine mutations were single or multiple nucleotide deletions that occurred inside the region complementary to the $5^{\prime}$ PCR primers used to amplify ORFs TP0252, TP0415, TP459, ТP0602, and TP0943. This resulted in a frameshift mutation in each of these ORFs. In addition, a frameshift mutation occurred in TP0536 due to a single nucleotide insertion within the region complementary to the $5^{\prime}$ primer used for amplification of this ORF. Two additional frameshift mutations occurred due to single base pair deletions within the coding sequences of TP0174 and TP0324. Finally, a single nucleotide substitution resulted in the generation of a STOP codon within the coding sequence of TP0117. The high frequency of mutations detected inside PCR primer regions (six of nine) indi-

Supplemental Materials. The average size of the ORFs that were not cloned is $1695 \mathrm{bp}$, whereas the average size ORF for the entire genome is $1013 \mathrm{bp}$. Therefore, a partial explanation for the failure to clone these ORFs may be related to the size of the PCR product. However, this is not a complete explanation in that several of the uncloned ORFs are average-sized or smaller. Another possibility is that these T. pallidum gene products are toxic when expressed in E. coli. Although the pUNI vector is designed to minimize transcription of the cloned insert in E. coli, it is possible that low levels of transcription of some genes occur, and these could have toxic effects (Liu et al. 1998).

\section{Characterization of the T. pallidum Univector Clone Set}

Because each of the ORFs was amplified by PCR prior to insertion into the univector, it is possible that errors exist in cates that quality control of PCR primer production is an important step that may improve the systematic cloning of any genome.

Of the 18 remaining mutations, six were single nucleotide substitutions that resulted in amino acid substitutions within ORFs TP0013, TP0074, ТP0350, TP0471, TP0711, and TP0782. An additional single nucleotide substitution was silent, whereas another occurred in the CACC sequence that is used for cloning but is not within the coding sequence of an ORF. The remaining 10 mutations were deletions at the 3 ' end of cloned genes. Three single nucleotide deletions were identified in clones TP0212, TP0692, and TP0792 that resulted in silent mutations because the next nucleotide maintains the stop codon. The seven other deletions involved multiple (two to six) nucleotides; however, all of these deletions impact only the last amino acid and/or the stop codon in the translated protein of ORFs TP0011, TP0074, TP0247, TP0260, TP0309, TP0389, and TP1031. 
A

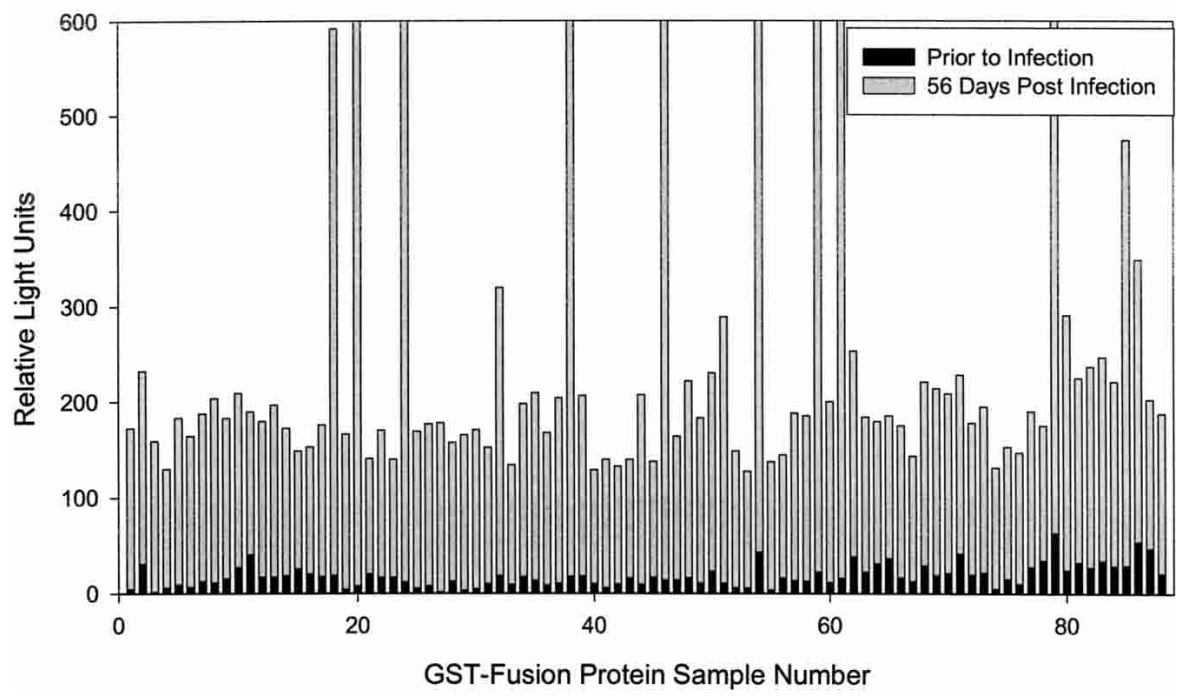

B

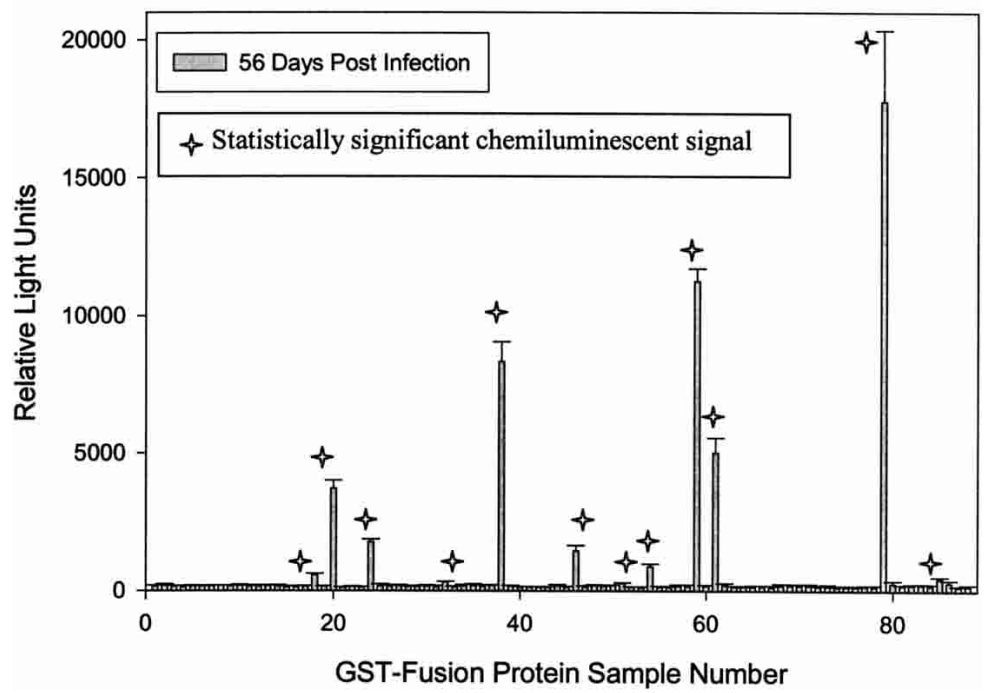

Figure 2 (A) Rapid identification of antigenic GST-fusion clones by a chemiluminescent immunoassay technique. Individual GST-fusion Treponema pallidum proteins from crude Escherichia coli extracts were selectively immobilized on glutathione-coated 96-well plates and were exposed to rabbit serum from rabbits either before or 2 months after intratesticular injection with virulent $T$. pallidum. Detection of binding interactions between rabbit $\lg G$ antibody and immobilized $T$. pallidum proteins was carried out with donkey, anti-rabbit IgG antibody conjugated to horseradish peroxidase. A plate reader monitored chemiluminescence, and the mean relative signal is presented for $85 \mathrm{~T}$. pallidum fusion proteins, samples 3-87. Sample numbers 1 and 2 were prepared from E. coli that does not express a fusion protein. Sample 88 is the Borrelia burgdorferi fibronectin binding protein (BBK32) fused to GST expressed from pMM110-pUNI-D. (B) The mean relative signal and SD data for rabbit serum collected 2 months after intratesticular injection of T. pallidum is presented. A star has been placed above each of the 12 samples with a statistically significant signal.

\section{Conversion of $T$. pallidum Clone Set to glutathione-S-transferase-Fusion Protein Expression Vector}

As described above, the univector plasmids can be fused with pHOST plasmids to create functional vectors. In vitro Cre-loxP recombination was used to generate a set of protein expression vectors by fusing the T. pallidum pUNI-D clone set with a pHOST vector designed for high-level protein expression. The set of $T$. pallidum pUNI-D clones predicted to contain a signal sequence were fused in individual reactions with a $\mathrm{pHOST}$ vector, pMM110, containing the bacterial $\mathrm{P}_{\text {tac }}$ promoter and a glutathione-S-transferase (GST) tag sequence (Fig. 1). Properly fused pMM110-pUNI-D clones were verified by PCR using primers specific for the fusion constructs. Proteins that are fused to GST can be affinitypurified from crude $E$. coli lysates by using glutathione-coated ELISA plates and, subsequently, can be used to capture antigen-specific antibodies (SLehr et Lal. 2001).

Currently, there is no vaccine available for the prevention of syphilis (Weinstock et al. 1998). Although it is known that patients treated during the early stages of syphilis can be reinfected, other studies, such as the demonstration of complete protection against $T$. pallidum infection in rabbits, indicate a vaccine is feasible (Miller 1973). The likelihood of developing a practical immunization regime is also supported by reports of partial protection against intradermal challenge as a result of immunizations with protein 4D (Borenstein et al. 1988), endoflagella (Champion et al. 1990), TmpB (Wicher et al. 1991), TprK (Centurion-Lara et al. 1999), and Tpn92 (Cameron et al. 2000). Therefore, it may be possible to identify a combination of recombinant $T$. pallidum antigens that generate complete protection.

Over the past 25 years, identification and antigenic characterization of T. pallidum polypeptides has dominated $T$. pallidum research (Strugnell et al. 1990; Norris 1993). The use of sodium dodecyl sulfatepolyacrylamide gel electrophoresis (SDS-PAGE) and two-dimensional gel electrophoresis coupled with immunoblot technology advanced the discovery of $T$. pallidum antigenic proteins. In addition, improvements in outer membrane protein purification techniques (Blanco et al. 1994, 1999; Radolf et al. 1995) have led to the identification of potential outer membrane proteins (Blanco et al. 1997; Shevchenko et al. 1997) that may aid in vaccine development; however, there is considerable uncertainty regarding the purity of outer membrane preparations (Radolf 1995; Shevchenko et al. 1997). The use of recombinant DNA technology has played a role in advancing the antigenic analysis of $T$. pallidum (Cameron et al. 2000), but systematic cloning and expression studies have not been previously reported. 
To identify novel antigens, binding interactions between recombinant $T$. pallidum proteins and IgG antibodies present in rabbits infected with $T$. pallidum were examined. Expression of 85 GST-fusion proteins (a sample set from the proteins with predicted signal sequences) was carried out in $E$. coli cells grown in a 96-well format. The GST-fusion proteins present in E. coli cell lysates were incubated in ELISA wells coated with immobilized glutathione (Pierce), and washes were performed to reduce nonspecific binding interactions between $E$. coli proteins and the ELISA wells. The immobilized GST-fusion proteins were then exposed to serum collected from three rabbits both before inoculation (normal rabbit serum [NRS]) and 2 months after intratesticular injection of T. pallidum (infected rabbit serum [IRS]). Detection of interactions between rabbit IgG antibody and recombinant fusion proteins was accomplished by chemiluminescence with donkey antirabbit IgG antibody conjugated to horseradish peroxidase (HRP).

The IgG binding data obtained by ELISA (Fig. 2A) indicates that rabbit serum collected prior to $T$. pallidum infection contains little or no antibody that specifically binds to $T$. pallidum proteins. Further, the data indicate that significant binding interactions occur between IgG antibodies present in rabbit serum collected 2 months after T. pallidum injection and several immobilized $T$. pallidum proteins (Fig. 2B). There is a striking difference between the binding interactions detected between the two serum types. For example, the mean level of binding of antibody infected rabbits to proteins in $E$. coli control lysates that were grown without $T$. pallidum clones (sample numbers 1 and 2) was 10 times greater than that obtained using sera from uninfected rabbits (Fig. 2A). The difference between the two samples may be a result of nonspecific binding of $E$. coli proteins to ELISA wells that in turn capture E. coli-specific IgG antibodies. Alternatively, it is possible that intratesticular injections of virulent $T$. palldium act as an adjuvant and generate an immune response against $E$. coli proteins that increases IgG antibody concentrations. Finally, an increase in overall IgG antibody concentration may occur as a result of $T$. pallidum infection, which results in increased nonspecific binding of rabbit IgG antibodies to ELISA wells. In an attempt to eliminate IgG antibodies that recognize $E$. coli proteins and thereby decrease the background binding levels in the assay, the rabbit serum samples were preincubated with soluble E. coli proteins (Methods). This subtraction technique, along with the fusion protein purification step, allowed the capture and detection of $T$. pallidum-specific IgG antibodies from serum collected from rabbits 2 months after infection.

A total of 12 GST-fusion protein samples with the highest mean chemiluminescence proteins were identified as statistically relevant $T$. pallidum antigenic proteins based on a $t$ test for independent samples with $P$ scores of $P<0.001$ (Fig. 2B; Table 2). Seven of the 12 antigens have been previously identified by various methods. These proteins include TP0100 (thioredoxin-like protein; Radolf et al. 1995), TP0163 (TroA/ Tromp1; Hardham et al. 1997), TP0257 (glycerophosphodiester phosphodiesterase [GlpQ]; Radolf et al. 1995), TP0298 (exported protein TpN38; Stamm et al. 1996), TP0319 (membrane protein [tmpC]; Blanco et al. 1988), TP0326 (outer membrane protein Tp92; Cameron et al. 2000), and TP0435 (17-kD lipoprotein; Radolf et al. 1988). Five of these proteins-including TP0163, ТP0298, ТP0319, ТP0326, and TP0435-have been identified previously as surface-exposed proteins, although these classifications may not be accurate (Weinstock et al. 1998). Proteins TP0257 and TP0100 were initially identified in purified outer membrane proteins fractions, but there is also evidence that these protein are localized in the periplasmic space (Shevchenko et al. 1999). Partial protection with recombinant proteins TP0326 and TP0257 has been demonstrated (Cameron et al. 1998, 2000), whereas TP0435 is a known major antigen (Lukehart et al. 1986) but does not provide protection against infection (Centurion-Lara et al. 1997).

In contrast to the above clones, the GST-fusion of lipoprotein $15 \mathrm{kD}$ (Tpp15), a previously identified major treponemal antigen, was not bound significantly by IgG antibody in the IRS (Radolf et al. 1988). Therefore, the GST-Tpp15 represents a false-negative result in this experiment. A possible ex-

Table 2. Identity and Statistical Analysis of the 15 Treponema pallidum Genes Yielding the Highest Signal in a Chemiluminescent Immunoassay

\begin{tabular}{|c|c|c|c|c|c|c|}
\hline Gene & Name & $\begin{array}{l}\text { Sample } \\
\text { number }\end{array}$ & $\begin{array}{l}\text { Predicted protein } \\
\text { size }(k D)\end{array}$ & Mean $^{a}$ & St. dev & $P$ value \\
\hline TP0100 & thioredoxin-like protein & 20 & - $^{c}$ & 3709.2 & 294 & $<0.001$ \\
\hline TP0163 & ABC transporter (TroA, Tromp1) & 32 & 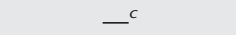 & 300.7 & 36 & $<0.001$ \\
\hline TP0257 & glycerophosphoryldiester phosphodiesterase (GlpQ) & 46 & 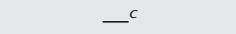 & 1447.7 & 94 & $<0.001$ \\
\hline TP0298 & exported protein $\mathrm{TpN} 38$ & 51 & - $^{c}$ & 277.7 & 16.5 & $<0.001$ \\
\hline TP0319 & membrane lipoprotein (TmpC) & 59 & ـ $^{c}$ & 11259.1 & 452 & $<0.001$ \\
\hline TP0326 & outer membrane protein & 61 & - $^{c}$ & 5017.7 & 550 & $<0.001$ \\
\hline TP0435 & lipoprotein, 17 kD (Tpp17) & 79 & - $^{c}$ & 17765.6 & 2583 & $<0.001$ \\
\hline TP0088 & conserved hypothetical protein & 18 & 23 & 572.4 & 49 & $<0.001$ \\
\hline TP0133 & hypothetical protein & 24 & 43 & 1769.3 & 91 & $<0.001$ \\
\hline TP0183 & hypothetical protein & 38 & 31 & 8338.6 & 705 & $<0.001$ \\
\hline TP0307 & conserved hypothetical protein & 54 & 37 & 880.9 & 105 & $<0.001$ \\
\hline $\mathrm{TP}^{2} 327^{b}$ & hypothetical protein & 62 & 20 & 214.1 & 58 & 0.198 \\
\hline TP0456 $6^{b}$ & hypothetical protein & 80 & 47 & 265.7 & 102 & 0.023 \\
\hline TP0469 & conserved hypothetical protein & 85 & 54 & 444.4 & 69 & $<0.001$ \\
\hline TP0470 $0^{b}$ & conserved hypothetical protein & 86 & 43 & 294.7 & 101 & 0.0034 \\
\hline
\end{tabular}

${ }^{a}$ Mean value units correspond to relative light units detected.

${ }^{b}$ Gene identified as statistically insignificant.

Predicted protein size was not included for previously characterized genes. 
A

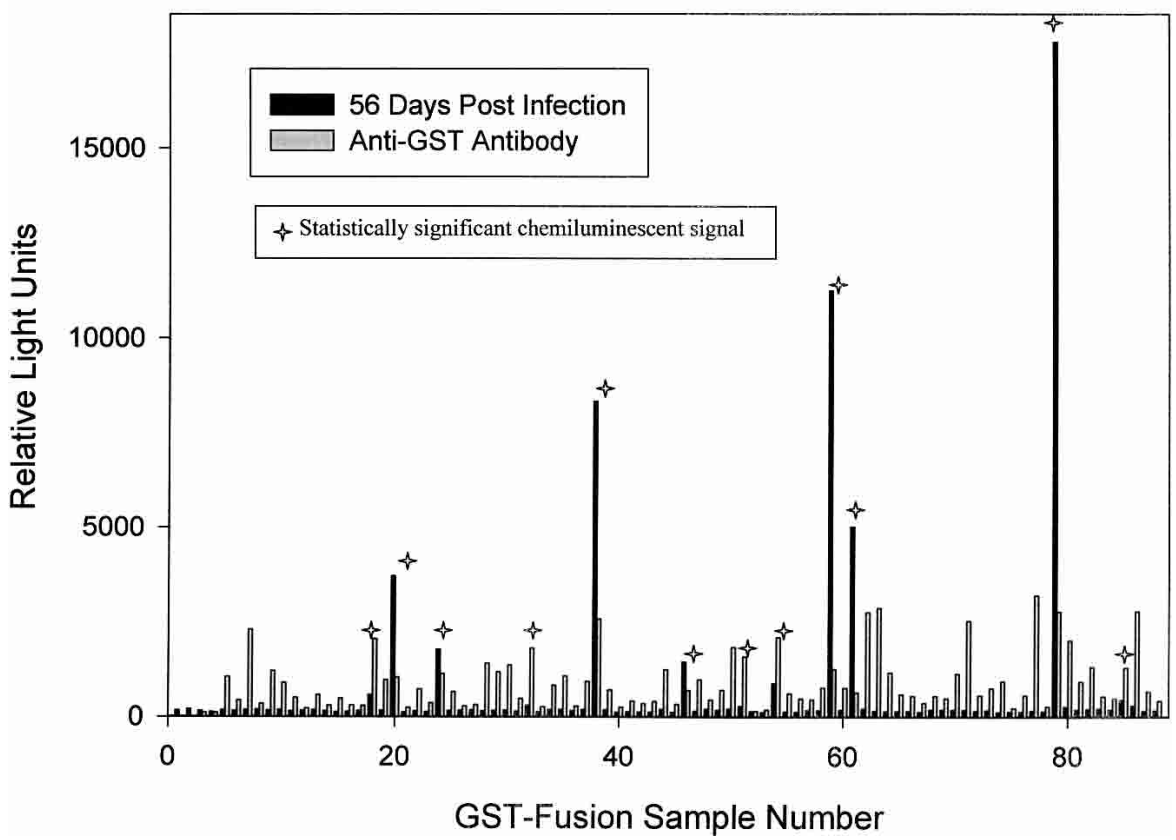

B

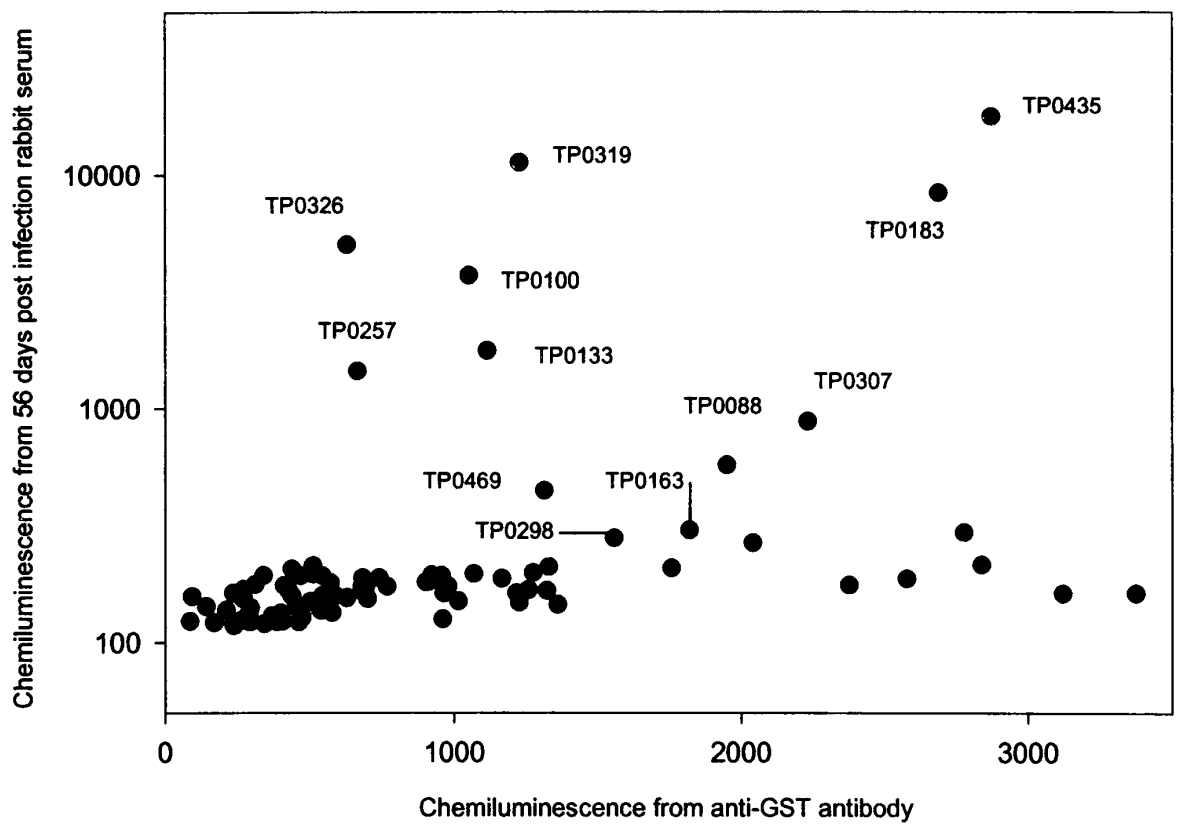

Figure 3 (A) Comparison of the chemiluminescent signal generated from exposing immobilized GST-fusion proteins to either anti-GST-HRP or serum from rabbits $56 \mathrm{~d}$ after Treponema pallidum infection. As described in Fig. 2A, GST-fusion proteins from crude Escherichia coli extracts were selectively immobilized on glutathione-coated 96 -well plates. To compare relative amounts of immobilized GST-fusion protein, anti-GST-HRP antibody was incubated in the wells instead of rabbit serum. A plate reader monitored chemiluminescence and the mean relative signal is presented next to the chemiluminescent signal measured in the immunoassay technique (Fig. 2B). A star has been placed above each of the 12 samples with a statistically significant signal (Table 2). (B) A scatter plot presents the absence of a correlation between GST-fusion protein amount and antigenic properties. The mean relative chemiluminescent signal detected from captured anti-GST-HRP antibody is plotted along the $X$-axis. The mean relative chemiluminescent signal detected from captured $\operatorname{lgG}$ antibodies present in rabbit serum $56 \mathrm{~d}$ after T. pallidum infection is plotted along the $Y$-axis in log scale. Samples with a statistically significant signal have been labeled (Table 2). planation for this result is that the fusion protein is poorly expressed. However, DNA sequence data on the Tpp15 (ORF TP0171) univector construct indicated that no mutations are present in the cloned gene. In addition, immunoblot experiments using an anti-GST antibody indicated the full-length GSTTpp15 fusion protein was present in E. coli BL21*DE3 cell lysates separated by SDS-PAGE (data not shown). Finally, the immobilized GST-fusion protein was detected by anti-GST antibody in the ELISA wells of glutathione-coated plates (Fig. 3A). Thus, it is unclear why this known antigen did not capture more IgG antibody.

Five previously unreported antigens (ТP088, ТР0133, ТР0183, TP0307, and TP0469) were found to bind significant amounts of IgG in the sera from infected rabbits. Interestingly, none of these proteins have been assigned a biological function. Protein TP0088, a conserved hypothetical protein, shares identity to only one known protein, the Borrelia burgdorferi conserved hypothetical protein, BB0662. Residues 55-170 are 24\% identical to BB0662, but neither TP0088 nor BB0662 has a predicted biological function.

Protein TP0133, a hypothetical lipoprotein, shares significant identity to four other T. pallidum hypothetical lipoproteins, including TP0134, TP0136, and TP0462. Proteins TP0133 and TP0134 appear to be closely related because residues $8-140$ of protein TP0133 are $49 \%$ identical to residues $6-376$ of protein TP0134. Protein TP0133 also appears related to proteins TP0462, sharing 38\% identity between residues $12-410$ of protein TP133 and residues 1-392 of protein TP0462. Protein TP0462 was also among the 85 proteins assayed in this experiment, and despite the sequence homology with TP0133, protein TP0462 did not bind significant amounts of antibody from the sera from infected rabbits. However, the sequence of clone TP0462 has not been analyzed; therefore, it is possible that a mutation in this construct may reduce protein expression. Lastly, residues $6-151$ of protein TP0133 are 51\% identical to residues 3-146 of protein TP0136.

The binding interactions de- 
tected between immobilized protein TP0183 and rabbit IgG generated the third highest chemiluminescent signal after that of proteins TP0453 and TP0319 (Fig. 2B). It is difficult to make quantitative conclusions about binding interactions because this screen does not normalize for the quantity of immobilized fusion protein for each gene examined, but the observed robustness of the chemiluminescent signal generated by proteins TP0183 and TP0435, the latter of which is known to elicit a strong immune response in rabbits (Lukehart et al. 1986), indicates that TP0183 may also be a major antigenic protein. It is possible that protein TP0183 is expressed at low levels in $T$. pallidum, thereby escaping prior detection on T. pallidum immunoblots. The TP0183 protein, however, does not exhibit significant sequence homology with other proteins, and so, no putative biological function can be assigned.

Although the most significant sequence homology of TP0307 is with a B. burgdorferi hypothetical protein of unknown function, other sequence alignment data for protein TP0307 indicates a putative function as a kinase, as well as a possible subcellular location on the outer membrane. Residues 33-191 of protein TP0307 are 30\% identical to residues 441-593 of the Streptomyces toyocaensis eukaryotic-type serine/ threonine kinase. In addition, residues 5-201 of protein TP0307 are $22 \%$ identical to residues $12-214$ of a Leptospira interrogans putative outer membrane protein. The fact that TP0307 reacts with the sera and has homology with an outer membrane protein makes this an interesting candidate for immune protection studies.

Of all the previously unreported antigens identified here, protein TP0469 appears to be the most conserved. Of the 989 sequence alignments identified in database searches, 186 possess a low enough $E$ value to qualify as significant. Multiple alignments to proteins such as Methanothermobacter thermautotrophicus $\mathrm{O}$-linked $\mathrm{N}$-acetylglucosamine transferase indicate this as a putative function of protein TP0469. In addition, protein TP0469 has sequence identity to several proteins containing tetratricopeptide repeats. Lastly, residues $233-472$ of protein TP0469 are 21\% identical to residues 719-949 of $B$. burgdorferi surface-located membrane protein 1 (lmp1).

Further investigations into these putative antigenic proteins are necessary to determine their relative antigenicity and potential protective activity. However, the fact that several well-characterized $T$. pallidum antigens were identified by the same method lends support to the findings and indicates that these antigens should be treated as potential vaccine candidates.

Antigenic characterization experiments were accomplished by exposing T. pallidum proteins fused to GST to serum from rabbits $56 \mathrm{~d}$ after $T$. pallidum infection. Current protein quantitation techniques are not sensitive enough to accurately quantify the amount of fusion protein immobilized to the glutathione-coated plate. However, it is important to determine whether there is a relationship between the amounts of protein immobilized and the amounts of rabbit IgG antibody captured by the GST-fusion protein. For example, if the proteins that resulted in the strongest binding signal with antibody were also present at much higher levels than other proteins tested, it would indicate that the signal being detected is simply an increase in nonspecific binding due to increased amount of protein. Similarly, if a protein is not expressed, it cannot bind antibody and will yield a falsenegative result in the ELISA experiment.

The relative amount of $T$. pallidum fusion proteins im- mobilized in the ELISA wells was estimated by using an antiGST antibody to detect the GST tag that is common to all of the fusions. The methods used to immobilize T. pallidum-GST fusion proteins on glutathione-coated wells for quantitation were identical to those used in the antigenic characterization experiments. However, instead of exposing immobilized protein to rabbit serum, an anti-GST antibody was used. Nonspecific antibody binding interactions were washed away before the HRP substrate was added to each well in order to detect chemiluminescence generated from captured HRP. The chemiluminescent signal was compared with the signal generated from captured IgG antibody present in serum from rabbits $56 \mathrm{~d}$ after $T$. pallidum infection (Fig. 3A). A scatter plot (Fig. 3B) demonstrates that there is no correlation between the amount of GST-fusion protein immobilized and the amount of IgG antibody captured by the immobilized GSTfusion proteins. Many of the E. coli extracts tested contained relatively low quantities of the $T$. pallidum-GST fusion proteins, based on low anti-GST reactivities (Fig. 3). This low reactivity could be due to poor transcription and or translation of the fusion product, or to proteolytic degradation of the product. Those fusion proteins that are present at low levels could potentially yield false-negative results. Thus one of the goals in future studies will be to achieve more uniform levels of the fusion products. However, it is notable that two of the gene products, TP0326 and TP0257, were highly reactive with sera from $T$. pallidum-infected rabbits and demonstrated relatively low reactivity with anti-GST (Fig. 3B). Furthermore, several proteins are expressed at high levels but do not exhibit marked reactivity with anti-T. pallidum antibodies (Fig. 3B).

Taken together, these results indicate that high reactivity with anti-T. pallidum antibodies is a reliable indicator of high antigenicity in this system, whereas low reactivity could be due to either low antigenicity or low fusion protein levels. This is a common limitation in most recombinant antigen screening techniques (e.g., colony immunoblot assays), and this report represents the first attempt to approach this problem quantitatively.

The above experiments indicate that the $T$. pallidum clone set will be a powerful reagent for functional genomics studies of T. pallidum biology and pathogenesis. The availability of the clone set permits the systematic evaluation of antigenicity of T. pallidum proteins. In addition, the ELISA experiments described above can be used to detect other types of protein-protein or protein ligand interactions. The clone set can also be used to examine binding interactions in vivo by using two-hybrid approaches to generate large-scale proteinprotein interaction maps. Such tools are important for an organism that cannot be cultured in vitro and is therefore recalcitrant to most molecular genetic approaches for the study of gene function and pathogenesis.

\section{METHODS}

\section{Bacterial Strains and Plasmids}

Chemically competent E. coli PIR1 (Liu et al. 1998) were provided by Invitrogen, Inc., and were used to propagate the univector plasmid DNA containing the cloned T. pallidum ORFs. E. coli BL21* DE3 (Invitrogen, Inc.) was used to propagate univector-host fusion plasmid DNA after Cre-loxP recombinase reactions and to express all of the GST-fusion proteins. The vector pUNI-D/V5-His-TOPO (referred to as pUNI-D in Results and Discussion) was provided by Invitrogen, Inc., and was used for the insertion of all T. pallidum PCR products. The 
vector pMM110 was created by inserting a loxP site into the Xhol-NotI site of pGex-4t-2 (Amersham Biosciences) and was used as the host vector for expression of all GST-tagged T. pallidum proteins.

\section{Media}

Immediately after heat-shock transformation, $E$. coli PIR1 was grown in media containing $5 \mathrm{~g}$ Bacto-Yeast, $20 \mathrm{~g}$ BactoTryptone, $5 \mathrm{M} \mathrm{NaCl}(2 \mathrm{~mL}), 0.19 \mathrm{~g} \mathrm{KCl}, 10 \mathrm{~mL}, 1 \mathrm{M} \mathrm{MgCl}_{2}, 10$ $\mathrm{mL} 1 \mathrm{M} \mathrm{MgSO}_{4}$, and $3.6 \mathrm{~g}$ glucose per liter (SOC). E. coli PIR1 cells containing pUNI-D with or without $T$. pallidum DNA inserts were grown overnight on LB agar plates containing 25 $\mu \mathrm{g} / \mathrm{mL}$ kanamycin; isolated colonies were expanded by incubation in $3 \mathrm{~mL}$ of the corresponding liquid medium. Immediately after heat-shock transformation, E. coli BL21*DE3 cells were grown in media containing $16 \mathrm{~g}$ Bacto-Tryptone, $10 \mathrm{~g}$ Bacto-Yeast, and $5 \mathrm{~g} \mathrm{NaCl}$ per liter (2YT). E. coli BL21*DE3 cells containing the pMM110-pUNI-D plasmid fusion construct were selected on LB agar plates containing $25 \mu \mathrm{g} / \mathrm{mL}$ kanamycin and $100 \mu \mathrm{g} / \mathrm{mL}$ ampicillin. Clones were selected and cultured in the liquid media form of the same medium prior to storage.

\section{PCR Reactions}

Pfu DNA polymerase (Stratagene) was used to amplify T. pallidum ORFs for cloning into pUNI-D. AdvanTaq DNA polymerase (Clontech) was used to PCR amplify inserts for screening. Research Genetics provided all of the primers used to amplify the ORFs. The template DNA for the PCR reactions consisted of a set of large insert BAC clones encompassing the entire T. pallidum genome (Smajs et al. 2002). For the majority of cloning and screening PCR reactions, the thermocycle program was $1 \mathrm{~min}$ at $96^{\circ} \mathrm{C}$ and $4 \mathrm{~min}$ at $64^{\circ} \mathrm{C}$ for 30 cycles with a final 10 -min $64^{\circ} \mathrm{C}$ step.

\section{Topoisomerase Cloning}

Topoisomerase cloning reactions were carried out with $4 \mu \mathrm{L}$ of PCR product, mixed with $1 \mu \mathrm{L}$ of salt solution $(1.2 \mathrm{M} \mathrm{NaCl}$, $0.06 \mathrm{M} \mathrm{MgCl}_{2}$ ) and $1 \mu \mathrm{L}$ of topoisomerase-adapted pUNI-D for $5 \mathrm{~min}$ at room temperature. This entire reaction was added to chemical-competent E. coli PIR1 cells prepared and supplied by Invitrogen, Inc. Cells and DNA were incubated for $30 \mathrm{~min}$ on ice, heat-shocked for $30 \mathrm{~s}$ at $42^{\circ} \mathrm{C}$, and returned for $5 \mathrm{~min}$ on ice. A total of $250 \mu \mathrm{L}$ of SOC media was added to the cells, followed by a $1-\mathrm{h}$ recovery period at $37^{\circ} \mathrm{C}$. A total of $200 \mu \mathrm{L}$ of transformed cells was spread onto LB-kanamycin agar plates, which were then incubated overnight at $37^{\circ} \mathrm{C}$.

\section{PCR Screen for Recombinant Clones}

Kanamycin-resistant $E$. coli PIR 1 transformants were screened for the presence of recombinant $T$. pallidum genes in pUNI-D by using colony PCR. Autoclaved pipette tips were used to pick three to 12 colonies for each T. pallidum ORF to be tested. The tips were used to inoculate individual colonies into PCR tubes containing a PCR mixture that included a pUni-forward (Invitrogen) primer within the vector and a 3' (bottom strand) primer specific to the T. pallidum ORF being screened. Visualization of a PCR product corresponding to the size of the ORF plus $120 \mathrm{bp}$ indicated the insertion of the ORF in the correct orientation.

\section{Cre-loxP Recombinase Reactions}

Cre recombinase (New England Biolabs) was used to fuse the pUNI-D clones containing $T$. pallidum ORFs with the pMM110 plasmid. Host vector DNA was purified by using a cesium chloride gradient (Sambrook et al. 1989) and diluted to $50 \mathrm{ng} / \mu \mathrm{L}$ in water. Individual pUNI-D clones containing $T$. pallidum ORFs were used in Cre reactions for the construction of the GST fusion clone set; $150 \mathrm{ng}$ of pMM110 and $3 \mu \mathrm{L}$ of univector DNA were mixed with $1 \mu \mathrm{L}$ of Cre and $1.5 \mu \mathrm{L}$ of $10 \times$ Cre Buffer (New England Biolabs, Inc.). Cre reactions were incubated for $1 \mathrm{~h}$ at $37^{\circ} \mathrm{C}$, heat-killed for $10 \mathrm{~min}$ at $70^{\circ} \mathrm{C}$, and chilled to $4^{\circ} \mathrm{C}$. Chemically competent E. coli BL21*DE3 cells were added to the Cre reaction for transformation and selection. Cells and DNA were incubated for $30 \mathrm{~min}$ on ice, heat-shocked for $90 \mathrm{sec}$ at $42^{\circ} \mathrm{C}$, and returned for $5 \mathrm{~min}$ at ice; $200 \mu \mathrm{L}$ of $2 \mathrm{YT}$ media was added to the cells, followed by a 1-h recovery period at $37^{\circ} \mathrm{C}$; and then $200 \mu \mathrm{L}$ was then spread on LB-kanamycin-ampicillin plates that were incubated overnight at $37^{\circ} \mathrm{C}$. Colony PCR was used to identify E. coli BL21*DE3 cells containing Cre-loxP recombined pMM110pUNI-D fusion plasmids. Autoclaved pipette tips were used to pick one to 12 colonies for each cloned T. pallidum ORF. The tips were used to inoculate PCR tubes containing a PCR mixture that included a top-strand primer specific to the terminus of GST in pMM110 pGextop (5'-GGGCTGGCAAGCCAC GTTTGGTG-3') and pUni-reverse (Invitrogen). Visualization of a PCR product corresponding to the size of the ORF plus $250 \mathrm{bp}$ indicated the correct fusion of a $T$. pallidum ORFpUNI-D plasmid with pMM110.

\section{DNA Sequence Data Collection}

Sequence data was acquired from PCR products generated from PCR colony screening of the pMM110-pUNI-D constructs. The PCR primers pGextop and pUni-reverse (Invitrogen) were used in sequencing reactions in order to sequence the $5^{\prime}$ and $3^{\prime}$ end of each ORF. An Applied Biosystems 3100 Genetic Analyzer was used to analyze sequencing reactions. BLAST searches and some manual inspections were used to analyze sequence data. Twenty-three of the clones in which a mutation was found were resequenced in order to confirm the presence of the mutation.

\section{Rabbit Serum Preparation}

Rabbit serum was collected from adult male New Zealand White rabbits obtained from Myrtle's Rabbitry (Thompson Station, TN). Rabbits were housed individually at $18^{\circ} \mathrm{C}$ to $20^{\circ} \mathrm{C}$ and given antibiotic-free food and water. Rabbits were tested for evidence of Treponema paraluiscuniculi infection by using a Macro-Vue RPR card test (Becton-Dickinson). Only seronegative animals were included in this study. Three rabbits were each infected with $4 \times 10^{8} \mathrm{~T}$. pallidum Nichols strain organisms by intratesticular injection. Sera was collected $48 \mathrm{~h}$ before infection and $56 \mathrm{~d}$ after infection and were stored at $-80^{\circ} \mathrm{C}$ until use.

\section{Absorption of Anti-E. coli Protein Antibodies}

E. coli $\mathrm{BL} 21^{*} \mathrm{DE} 3$ was grown overnight at $37^{\circ} \mathrm{C}$ in $150 \mathrm{~mL}$ of $\mathrm{LB}$ liquid media. Cells were pelleted and freeze-thawed two times at $-80^{\circ} \mathrm{C}$. The cell pellet was resuspended in $5 \mathrm{~mL} \mathrm{TE}(\mathrm{pH} 8.0)$ and subjected to cell lysis with a French press. The lysate was centrifuged for $10 \mathrm{~min}$ at $13 \mathrm{~K}$ and $4^{\circ} \mathrm{C}$. A mixture of $45 \mu \mathrm{L}$ rabbit serum, $405 \mu \mathrm{L}$ PBS (pH 7.4), and $250 \mu \mathrm{L}$ BL21*DE3 cell lysate was rocked for $5 \mathrm{~h}$ at room temperature. Absorbed serum was stored at $-20^{\circ} \mathrm{C}$ until use.

\section{ELISA Protocol}

E. coli $\mathrm{BL} 21^{\star} \mathrm{DE} 3$ hosting the pMM110-pUNI-D constructs containing $T$. pallidum ORFs were inoculated into $1 \mathrm{~mL} \mathrm{LB}$ media containing $25 \mu \mathrm{g} / \mathrm{mL}$ kanamycin, $100 \mu \mathrm{g} / \mathrm{mL}$ ampicillin, and $2 \%$ glucose in a 96 -well format. Cultures were grown overnight with shaking at $37^{\circ} \mathrm{C}$. The next day, a $100 \mu \mathrm{L}$ aliquot of the overnight culture was added to $1.5 \mathrm{~mL} 2 \mathrm{YT}$ containing $25 \mu \mathrm{g} / \mathrm{mL}$ kanamycin and $100 \mu \mathrm{g} / \mathrm{mL}$ ampicillin. Cultures were grown for $4 \mathrm{~h}$ at $37^{\circ} \mathrm{C}$ on a shaker before IPTG was added to a final concentration of $0.5 \mathrm{mM}$. A 5 -h induction period continued on a shaker at $37^{\circ} \mathrm{C}$. Cells were pelleted and stored at $-80^{\circ} \mathrm{C}$. Each cell pellet was freeze-thawed three

\section{Genome Research


times at $-80^{\circ} \mathrm{C}$ before $0.3 \mathrm{~mL}$ B-PER (Pierce bacterial protein extraction reagent) containing $0.375 \mathrm{mg} / \mathrm{mL}$ lyzozyme and $\overline{4} 20 \mathrm{ng} / \mathrm{mL}^{-}$DNase I was used to lyse the pellet. The resuspended pellets were shaken vigorously for $10 \mathrm{~min}$ at room temperature while Reacti-Bind glutathione-coated white 96well pPlates (Pierce) were washed two times with $0.21 \mathrm{~mL}$ each of PBS (pH 7.4) and 0.05\% Tween 20 (wash buffer); 0.19 $\mathrm{mL}$ of cell lysates were then added to the glutathione-coated plates and incubated at room temperature for $2 \mathrm{~h}$. Plates were washed three times with $0.21 \mathrm{~mL}$ of wash buffer and then blocked in $0.21 \mathrm{~mL}$ PBS (pH 7.4) and 5\% dry milk for $1 \mathrm{~h}$ at room temperature. Prepared absorbed serum $(0.75 \mathrm{~mL})$ was diluted into $20 \mathrm{~mL}$ PBS ( $\mathrm{pH} 7.4$; final serum dilution is 1:444), and $0.19 \mathrm{~mL}$ of serum solution was added to each well for $3 \mathrm{~h}$ at room temperature. Plate wells were washed three times with $0.21 \mathrm{~mL}$ of wash buffer. A 1:2500 dilution of anti-rabbit Ig, HRP-linked $\mathrm{F}\left(\mathrm{ab}^{\prime}\right) 2$ fragment from donkey (Amersham Pharmacia) in wash buffer was added to each plate well for 1 $\mathrm{h}$ at room temperature. Each plate well was washed five times before $0.19 \mathrm{~mL}$ of SuperSignal ELISA Pico Chemiluminescent Substrate (PIERCE) was added. Light emission from each plate well was monitored at a 5- and 15-min interval with a Genios Plate Reader for $200 \mathrm{~ms}$. Each experiment was repeated three times. The resulting six measurements were used to generate a mean and SD for each sample. The same experimental procedures were used to measure the amount of immobilized GST-fusion proteins, except a 1:50,000 dilution of anti-GSTHRP (Pierce) was diluted in PBS (pH 7.4) and incubated in the ELISA wells for $1 \mathrm{~h}$ at room temperature before washing.

\section{ACKNOWLEDGMENTS}

We thank Invitrogen, Inc., for providing the pUNI-D vector adapted with topoisomerase and Research Genetics for providing the PCR primer set. In addition, we thank Steve Elledge for helpful advice. M.M. is supported in part through the Keck Center for Computational and Structural Biology, NLM Training Grant T15 LM07093. This work was supported by NIH grants AI45842 to T.P. and AI49552 to S.N.

The publication costs of this article were defrayed in part by payment of page charges. This article must therefore be hereby marked "advertisement" in accordance with 18 USC section 1734 solely to indicate this fact.

\section{REFERENCES}

Blanco, D.R., Champion, C.I., Miller, J.N., and Lovett, M.A. 1988. Antigenic and structural characterization of Treponema pallidum (Nichols strain) endoflagella. Infect. Immun. 56: 168-175.

Blanco, D.R., Reimann, K., Skare, J., Champion, C.I., Foley, D. Exner, M.M., Hancock, R.E., Miller, J.N., and Lovett, M.A. 1994. Isolation of the outer membranes from Treponema pallidum and Treponema vincentii. J. Bacteriol. 176: 6088-6099.

Blanco, D.R., Miller, J.N., and Lovett, M.A. 1997. Surface antigens of the syphilis spirochete and their potential as virulence determinants. Emerg. Infect. Dis. 3: 11-20.

Blanco, D.R., Champion, C.I., Lewinski, M.A., Shang, E.S., Simkins, S.G., Miller, J.N., and Lovett, M.A. 1999. Immunization with Treponema pallidum outer membrane vesicles induces high-titer complement-dependent treponemicidal activity and aggregation of $T$. pallidum rare outer membrane proteins (TROMPs). $J$. Immunol. 163: 2741-2746.

Borenstein, L.A., Radolf, J.D., Fehniger, T.E., Blanco, D.R., Miller, J.N., and Lovett, M.A. 1988. Immunization of rabbits with recombinant Treponema pallidum surface antigen $4 \mathrm{D}$ alters the course of experimental syphilis. J. Immunol. 140: 2415-2421.

Cameron, C.E., Castro, C., Lukehart, S.A., and Van Voorhis, W.C. 1998. Function and protective capacity of Treponema pallidum subsp. pallidum glycerophosphodiester phosphodiesterase. Infect. Immun. 66: 5763-5770.

Cameron, C.E., Lukehart, S.A., Castro, C., Molini, B., Godornes, C., and Van Voorhis, W.C. 2000. Opsonic potential, protective capacity, and sequence conservation of the Treponema pallidum subspecies pallidum Tp92. J. Infect. Dis. 181: 1401-1413.
Centurion-Lara, A., Arroll, T., Castillo, R., Shaffer, J.M., Castro, C., Van Voorhis, W.C., and Lukehart, S.A. 1997. Conservation of the 15-kilodalton lipoprotein among Treponema pallidum subspecies and strains and other pathogenic treponemes: Genetic and antigenic analyses. Infect. Immun. 65: 1440-1444.

Centurion-Lara, A., Castro, C., Barrett, L., Cameron, C., Mostowfi, M., Van Voorhis, W.C., and Lukehart, S.A. 1999. Treponema pallidum major sheath protein homologue Tpr $\mathrm{K}$ is a target of opsonic antibody and the protective immune response. J. Exp. Med. 189: 647-656.

Champion, C.I., Miller, J.N., Borenstein, L.A., Lovett, M.A., and Blanco, D.R. 1990. Immunization with Treponema pallidum endoflagella alters the course of experimental rabbit syphilis. Infect. Immun. 58: 3158-3161.

Fraser, C.M., Norris, S.J., Weinstock, G.M., White, O., Sutton, G.G., Dodson, R., Gwinn, M., Hickey, E.K., Clayton, R., Ketchum, K.A., et al. 1998. Complete genome sequence of Treponema pallidum, the syphilis spirochete. Science 281: 375-388.

Hardham, J.M., Stamm, L.V., Porcella, S.F., Frye, J.G., Barnes, N.Y., Howell, J.K., Mueller, S.L., Radolf, J.D., Weinstock, G.M., and Norris, S.J. 1997. Identification and transcriptional analysis of a Treponema pallidum operon encoding a putative $\mathrm{ABC}$ transport system, an iron-activated repressor protein homolog, and a glycolytic pathway enzyme homolog. Gene 197: 47-64.

Liu, Q., Li, M.Z., Leibham, D., Cortez, D., and Elledge, S.J. 1998. The univector plasmid-fusion system, a method for rapid construction of recombinant DNA without restriction enzymes. Curr. Biol. 8: 1300-1309.

Lukehart, S.A., Baker-Zander, S.A., and Sell, S. 1986. Characterization of the humoral immune response of the rabbit to antigens of Treponema pallidum after experimental infection and therapy. Sex. Transm. Dis. 13: 9-15.

Miller, J.N. 1973. Immunity in experimental syphilis, VI: Successful vaccination of rabbits with Treponema pallidum, Nichols strain, attenuated by irradiation. J. Immunol. 110: 1206-1215.

Norris, S.J. 1993. Polypeptides of Treponema pallidum: Progress toward understanding their structural, functional, and immunologic roles. Treponema Pallidum Polypeptide Research Group. Microbiol. Rev. 57: 750-779.

Norris, S.J., Cox, D.L., and Weinstock, G.M. 2001. Biology of Treponema pallidum: Correlation of functional activities with genome sequence data. J. Mol. Microbiol. Biotechnol. 3: 37-62.

Radolf, J.D. 1995. Treponema pallidum and the quest for outer membrane proteins. Mol. Microbiol. 16: 1067-1073.

Radolf, J.D., Chamberlain, N.R., Clausell, A., and Norgard, M.V. 1988. Identification and localization of integral membrane proteins of virulent Treponema pallidum subsp. pallidum by phase partitioning with the nonionic detergent triton X-114. Infect. Immun. 56: 490-498.

Radolf, J.D., Robinson, E.J., Bourell, K.W., Akins, D.R., Porcella, S.F., Weigel, L.M., Jones, J.D., and Norgard, M.V. 1995. Characterization of outer membranes isolated from Treponema pallidum, the syphilis spirochete. Infect. Immun. 63: 4244-4252.

Sambrook, J., Maniatis, T., and Fritsch, E.F. 1989. Molecular cloning : A laboratory manual, 2nd ed. Cold Spring Harbor Laboratory Press, Cold Spring Harbor, NY.

Sehr, P., Zumbach, K., and Pawlita, M. 2001. A generic capture ELISA for recombinant proteins fused to glutathione S-transferase: Validation for HPV serology. J. Immunol. Meth. 253: 153-162.

Shevchenko, D.V., Akins, D.R., Robinson, E.J., Li, M., Shevchenko, O.V., and Radolf, J.D. 1997. Identification of homologs for thioredoxin, peptidyl prolyl cis-trans isomerase, and glycerophosphodiester phosphodiesterase in outer membrane fractions from Treponema pallidum, the syphilis spirochete. Infect. Immun. 65: 4179-4189.

Shevchenko, D.V., Sellati, T.J., Cox, D.L., Shevchenko, O.V., Robinson, E.J., and Radolf, J.D. 1999. Membrane topology and cellular location of the Treponema pallidum glycerophosphodiester phosphodiesterase (GlpQ) ortholog. Infect. Immun. 67: 2266-2276.

Shuman, S. 1994. Novel approach to molecular cloning and polynucleotide synthesis using vaccinia DNA topoisomerase. $J$. Biol. Chem. 269: 32678-32684.

Smajs, D., McKevitt, M., Wang, L., Howell, J.K., Norris, S.J., Palzkill, T., and Weinstock, G.M. 2002. BAC library of T. pallidum DNA in E. coli. Genome Res. 12: 515-522.

Stamm, L.V., Hardham, J.M., and Frye, J.G. 1996. Expression and sequence analysis of a Treponema pallidum gene, tpn38(b), encoding an exported protein with homology to T. pallidum and Borrelia burgdorferi proteins. FEMS Microbiol. Lett. 135: 57-63. 


\section{McKevitt et al.}

Sternberg, N., Hamilton, D., Austin, S., Yarmolinsky, M., and Hoess, R. 1981. Site-specific recombination and its role in the life cycle of bacteriophage P1. Cold Spring Harb. Symp. Quant. Biol. 45: $297-309$.

Strugnell, R., Cockayne, A., and Penn, C.W. 1990. Molecular and antigenic analysis of treponemes. Crit. Rev. Microbiol. 17: $231-250$.

Weinstock, G.M., Hardham, J.M., McLeod, M.P., Sodergren, E.J., and Norris, S.J. 1998. The genome of Treponema pallidum: New light on the agent of syphilis. FEMS Microbiol. Rev. 22: 323-332.

Wicher, K., Schouls, L.M., Wicher, V., Van Embden, J.D., and Nakeeb, S.S. 1991. Immunization of guinea pigs with recombinant TmpB antigen induces protection against challenge infection with Treponema pallidum Nichols. Infect. Immun.

59: 4343-4348.

\section{WEB SITE REFERENCES}

http://www.cbs.dtu.dk/services/SignalP/; SignalP program.

Received March 19, 2002; accepted in revised form April 22, 2003

\section{Genome Research}




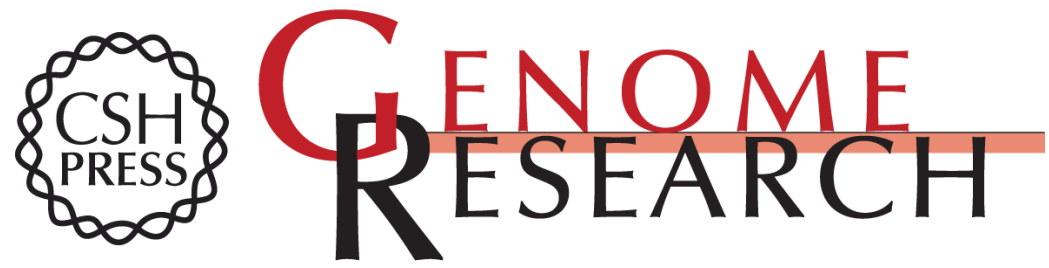

\section{Systematic Cloning of Treponema pallidum Open Reading Frames for Protein Expression and Antigen Discovery}

Matthew McKevitt, Krupa Patel, David Smajs, et al.

Genome Res. 2003 13: 1665-1674

Access the most recent version at doi:10.1101/gr.288103

Supplemental Material

References

License

Email Alerting Service
http://genome.cshlp.org/content/suppl/2003/06/12/288103.DC1

This article cites 29 articles, 18 of which can be accessed free at: http://genome.cshlp.org/content/13/7/1665.full.html\#ref-list-1

Receive free email alerts when new articles cite this article - sign up in the box at the top right corner of the article or click here.

\section{Affordable, Accurate Sequencing.}

